\title{
Epidemiological Study of Hepatitis $B, C$ and HIV Cases among the Foreigners Visiting Sulaimani City from 2013 Through 2016
}

\author{
Mohammed Omer Mohammed \\ Dep.of Medicine \\ College of Medicine \\ University of Sulaimani \\ Sulaimani, Iraq \\ Mohammed.raheem@univsul.edu.iq \\ Fenk Bakir Maarouf \\ College of Medicine \\ University of Sulaimani \\ Sulaimani, Iraq \\ fenk.maaarouf@univsul.edu.iq
}

\author{
Asan Baram Hasan \\ Directorate of Health \\ Ministry of Health \\ Sulaimani, Iraq \\ asanbaram@yahoo.com
}

Volume 4 - Special Issue:

3rd International

Abstract

Conference on Health \&

Hepatitis B, C and HIV infections present a great public

Medical Sciences: Insight

into Advanced Medical

Research (ICHMS 2019)

health problem worldwide. More than 350 million of world's populations have chronic $\mathrm{HBV}$ infection and near 1 million people are dying due to this infection each year. About 150-200 million of world's population have chronic HCV infection that leads to nearly 350 000 deaths annually. On the other hand HIV remains

DOI: as a major global public health issue. In 2015, about

10.24017/science.2019 .ICHMS.23

36.7 million people were living with HIV and 1.1 million people died of $\mathrm{HIV}$ related illnesses.

Received:

19 June 2019

To find the prevalence of $\mathrm{HB}, \mathrm{HCV}$ and $\mathrm{HIV}$ infection among the foreigners who visited Sulaimani city in 2013 through 2016 and evaluate the common risk factors in those who had a positive results in 2016. This

Accepted:

10 July 2019 study was conducted between $1^{\text {st }}$ of January 2016 and $31^{\text {st }}$ December 2016. A total number of 275,979 foreigners who were referred formally to the central laboratory- residency department in Sulaimani city for screening for (HBsAg, HCV Ab and $\mathrm{HIV} A b)$ from 2013 through 2016 were analyzed and all the foreigners who visited Sulaimani city in 2016 were included with 


\begin{abstract}
assessment of demographic data and risk factors among the positive cases.

Among 275,979 foreigners who visited Sulaimani city from 2013 through 2016, theoverall prevalence of $\mathrm{HBV}$ infection was $0.47 \%(1318$ cases), HCV $0.01 \%$ ( 267 cases) and HIV $0.01 \%$ ( 30 cases). In 2016 the highest prevalence of $\mathrm{HBV}$ infection was among Syrians which was $2.5 \%$ while highest $\mathrm{HCV}$ prevalence was among Europeans $0.82 \%$. Ages of the patients ranged between (18-65) years, $85.4 \%$ were males, $65.2 \%$ of males and 45.7\% of females were married. Dental procedures, surgery, blood transfusion and family history were common risk factors.

HBV infection was highest among Syrian foreigners. While the highest HCV prevalence was among Europeans. An immediate action plan is needed to screen all Syrian refugees in our region for $\mathrm{HBV}, \mathrm{HCV}$ and HIV to determine active infection and treat accordingly and also impose preventive measures to halt the spread of the infections.
\end{abstract}

Keywords: Hepatitis B, Hepatitis C, HIV, Prevalence, Foreigners,Sulaimani

\title{
1. INTRODUCTION
}

Hepatitis B is a potentially life-threatening liver infection. It is a global health problem. It can cause acute and chronic infection and puts people at high risk of death from cirrhosis and liver cancer. It is 50-100 folds more infectious than human immunodeficiency virus (HIV) and 10 folds more infectious than hepatitis $\mathrm{C}$ virus (HCV) [1]. An exposure to an infected source has a risk of acute infection up to $30 \%$. Worldwide about two billion people have been infected with HBV and more than 350 million have chronic liver infection. About 500 000-1.2 million people pass away annually because of the acute or chronic hepatitis B [2].

HBV is a Hepadna virus, the virion consisting of a 42-nm spherical, double-shelled particle that invades the hepatocytes [3], [4].

The prevalence of chronic HBV infection varies greatly in different parts of the world. The world are divided into three regions where the prevalence of chronic HBV infection is high $(\geq 8 \%)$, intermediate $(2-7 \%)$, and low $(<2 \%)$ [5].

According to the previous studies done in Sulaimani city the prevalence of HBV infection was $0.67 \%$ among the premarital couples in 2012 [6], 0.7\% among 17182 patients who had screening with HBsAg preoperatively [7], and $0.78 \%$ among 7900 blood donors in Duhok city [8] puts our region in a low endemicity area.

Transmission results from exposure to infectious blood or body fluids containing HBV [9]. The virus may be detected within 4-8 weeks after infection and can persist and leads to chronic hepatitis B. The incubation period of the HBV vary from 30 to 180 days [10].

The hepatitis B surface antigen (HBsAg) is most frequently used to screen for the presence of infection. It is the first detectable viral antigen to appear during infection [11].

Vaccines for the prevention of HBV are routinely recommended for infants since 1991 in the United States [12]. A protective response to the vaccine is defined as HBs antibody concentration of at least $10 \mathrm{MiU} / \mathrm{ml}$ in the recipient's serum [13]. 
Hepatitis C virus causes both acute and chronic infection. Acute HCV infection is usually asymptomatic. About $15-45 \%$ of infected persons spontaneously clear the virus within 6 months without any treatment. The remaining 55-85\% of persons develops chronic HCV infection. In patients with chronic HCV infection, the risk of liver cirrhosis is between 15 $30 \%$ within 20 years. About 3-4 million people are infected annually, and more than 350,000 people die annually from hepatitis C related diseases [14].

It is estimated that 150-200 million people are living with chronic hepatitis C [14], [15]. The infection rates have increased substantially in the 20th century due to intravenous drug abuse and reused but poorly sterilized medical instruments [16].

Countries with high rates of infection include Egypt (22\%), Pakistan (4.8\%) and China (3.2\%) [14], the high prevalence in Egypt is due to a now-discontinued mass-treatment campaign for schistosomiasis using improperly sterilized glass syringes [16].

Several studies have been done in Kurdistan regarding the prevalence of HCV infection ,in Sulaimani city among 17182 patients who had screening with HCV Ab preoperatively the prevalence was $0.4 \%$ [7] and in Duhok city among 7900 blood donors the prevalence was $0.2 \%$ [8] putting our region in a low endemicity area.

The human immunodeficiency virus is a Lentivirus that causes HIV infection and over time acquired immunodeficiency syndrome (AIDS) [17], [18]. AIDS is characterized by progressive failure of the immune system that causes life-threatening opportunistic infections and cancers, average survival time after infection with HIV without therapy is estimated to be 9 to 11 years, depending on the subtype of HIV [19].

Around $40 \%$ of people living with HIV do not know that they have the virus. Since 2010, the incidence of new infections among adults $(15+)$ has remained static at 1.9 million [20].

Most of children live in Sub-Saharan Africa were infected via their HIV-positive mothers during pregnancy, childbirth or breastfeeding [21].

The specimens that are repeatedly reactive by ELISA and positive by IFA or reactive by western blot are considered HIV-positive and indicate HIV infection [22].

Aim of the study: to find out the prevalence of HBV, HCV and HIV infection among the foreigners visiting Sulaimani city formally since 2013 through 2016, and to assess the risk factors in those who visited Sulaimani city in 2016.

\section{SUBJECTS AND METHODS}

This study was performed between $1^{\text {st }}$ of January 2016 and $31^{\text {st }}$ of December 2016, all foreigners (visitors) who were referred formally to the central laboratory-Residency department in Sulaimani city for screening with (HBsAg, HCV Ab and HIV Ab) were included .

A questionnaire designed to collect demographic data in terms of age, sex, residency and risk factors for getting (HBV, HCV and HIV) infections like history of surgical and dental procedures and blood transfusion.

Study design:Composed of two parts:

A. Retrospective study in which all the foreigners who were referred formally to the central laboratory-residency department in 2013, 2014 and 2015 were included.

B. Prospective study in which all the foreigners who were referred formally to the central laboratory-residency department in 2016 were included with assessment of their demographic data and risk factors. 


\section{Ethical consideration:}

After the proposal of the study was approved by scientific committee of Kurdistan Board of Medical Specialties, permissions were obtained from directory of health and administrative authorities of Residency institute.

The aim and content of the study were explained for all positive subjects in 2016 and an informed consent was obtained from each of them. Participation was absolutely voluntary, personal autonomy was respected and all obtained information were coded anonymous and kept confidential. All positive cases were given information regarding their type of infection, mode of transmission, nature of the disease and possible complications. An educational printed handout (prepared by the researcher) prepared in three languages (Kurdish, Arabic and English) were given to the positive cases accordingly.

The questionnaire was filled by either a direct interview of the participants by researcher in the residency institute in a private room to keep the patients privacy or by telephone contact of those who couldn't attend the interview for any reason. All subjects who were sent formally to the central lab-residency department for screening with (HBsAg, HCV Ab and HIV Ab) who had positive results were included.

The questionnaire form include detailed history about their age, gender, residency, history of immunization for HBV, surgery, dental procedures, blood transfusion, Parenteral drug misuse, tattooing, other medical conditions, and family history of HBV, HCV, HIV infection

Five $\mathrm{mL}$ of venous blood was obtained from each participant using disposable syringes. Three $\mathrm{ml}$ of the serum was taken into two labeled sterile ependorf tubes, the first tube was used for detection of $\mathrm{HBsAg}, \mathrm{HCV} \mathrm{Ab}$ and $\mathrm{HIV} \mathrm{Ab}$ and the other tube stored and used for confirmation of the HBV, HCV and HIV positive cases. All infected utensils were properly disposed.

There were four types of automated instrument used in detecting HBsAg, HCV Ab and HIV $\mathrm{Ab}$ which were Cobas, Semen's, Vida's and liaison.

Whenever a suspicious case detected further study was done for confirmation, using other automated instruments. For HCV Ab and HIV Ab positive cases a further confirmatory test was done with western blot test.

Statistical analysis; using Statistical Package for the Social Science-23 was applied to identify descriptive analysis (the range, mean and standard deviation, Frequency and percentages). Chi square and unpaired $\mathrm{T}$ test were used to find association between age and other variables. $\mathrm{P}$ value $\leq 0.05$ regarded as a significant level.

\section{RESULTS}

A total number of 275979 foreigners who had visited Sulaimani Governorate and screened for HBV, HCV and HIV infection from (2013 through 2016) were retrospectively analyzed, and overall prevalence was $(4.7 / 1000)$ for HBV, ( 0.97/1000) for HCV and $(0.1 / 1000)$ for HIV infection, Table 1.

Table 1: The average prevalence of HBV, HCV and HIV in (2013 through 2016).

\begin{tabular}{|lccccc|}
\hline \multicolumn{2}{c}{ HBV+ve } & \multicolumn{2}{c}{ HCV+ve } & HIV+ve \\
\hline Number & Prev. & Number & Prev. & Number & Prev. \\
& $4.7 / 1000$ & 267 & $0.97 / 1000$ & 30 & $0.1 / 1000$ \\
\hline
\end{tabular}

The rate of HBV, HCV and HIV infection for each separate year and Trends in number of visitors and prevalence of different infections in each year, Table -2 and Fig. -1 . 
Table 2: Number of visitors and rate of infection in each yearbetween (2013-2016).

\begin{tabular}{|llllllll|}
\hline \multirow{2}{*}{ Year } & $\begin{array}{l}\text { Total } \\
\text { Visitors }\end{array}$ & \multicolumn{2}{l}{ HBV+ve } & \multicolumn{3}{l|}{ HCV+ve } & \multicolumn{3}{c|}{ HIV+ve } \\
\cline { 3 - 8 } & & $\mathrm{N}$ & $\begin{array}{l}\text { Prevalence } \\
\text { (per 1000) }\end{array}$ & $\mathrm{N}$ & $\begin{array}{l}\text { Prevalence } \\
\text { (Per 1000) }\end{array}$ & $\mathrm{N}$ & $\begin{array}{l}\text { Prevalence } \\
\text { (per 1000) }\end{array}$ \\
$\mathbf{2 0 1 3}$ & 98937 & 480 & 4.9 & 79 & 0.8 & 12 & 0.12 \\
$\mathbf{2 0 1 4}$ & 116838 & 364 & 3.1 & 89 & 0.76 & 12 & 0.1 \\
$\mathbf{2 0 1 5}$ & 40308 & 321 & 8 & 74 & 1.8 & 3 & 0.75 \\
$\mathbf{2 0 1 6}$ & 19896 & 153 & 7.7 & 25 & 1.25 & 3 & 1.5 \\
\hline
\end{tabular}

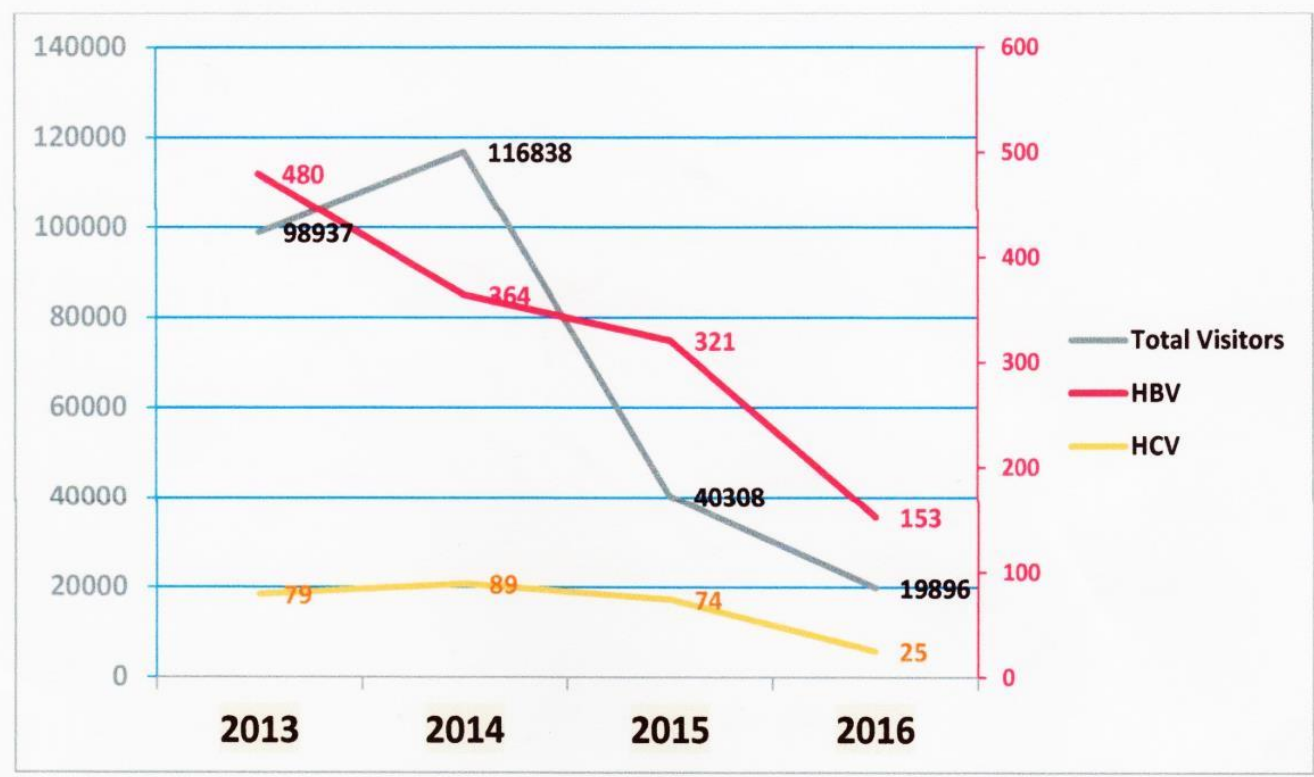

Figure 1: Trends in numbers of visitors and rate of infection from (2013) through (2016).

Of181 cases that had positive test results in 2016, the distribution of viral type was as follow: HBV $84.5 \%$, HCV $13.8 \%$ and HIV contributed to $1.7 \%$ of cases, Table 3.

Table 3: Distribution of viral type for a sample of 181 positive tests in 2016.

\begin{tabular}{|c|c|c|c|}
\hline \multirow[t]{5}{*}{ Virus } & & Frequency & Percent \\
\hline & HBV & 153 & 84.5 \\
\hline & HCV & 25 & 13.8 \\
\hline & HIV & 3 & 1.7 \\
\hline & Total & 181 & 100 \\
\hline
\end{tabular}

The number of visitors and prevalence of HBV and HCV Positive results among different countries in 2016, Table 4. 
Table 4: Prevalence of HBV and HCV among different countries in 2016.

\begin{tabular}{llllll}
\hline Country & $\begin{array}{l}\text { Visitors } \\
\text { (total) }\end{array}$ & HBV(=n) & HBV \%. & HCV(=n) & HCV \%. \\
\hline Turkey & 6100 & 29 & 0.48 & 1 & 0.016 \\
\hline Iran & 3625 & 8 & 0.2 & 6 & 0.16 \\
\hline $\begin{array}{l}\text { Indian } \\
\text { subcontinent }\end{array}$ & 3439 & 16 & 0.46 & 3 & 0.088 \\
\hline Syria & & & & & \\
\hline Far East & 2770 & 70 & 2.5 & 3 & 0.1 \\
\hline Egypt & 1745 & 16 & 0.9 & 2 & 0.11 \\
\hline Europe & 858 & 2 & 0.23 & 2 & 0.23 \\
\hline USA & 850 & 6 & 0.7 & 7 & 0.82 \\
\hline Others & 317 & 2 & 0.6 & non & Non \\
\hline
\end{tabular}

-Far East countries are: China, Korea,Japan,Indonesia, Malaysia and Philippines.

- Indian Subcontinentincludes:India,Pakistan, Bangladesh and Nepal.

-Others: Cambodia, Myanmar, Australia, Palestine, Sudan, Afghanistan.

The contribution of Different countries for HBV and HCV cases in 2016 are shown, Table -5.

Table 5: Contribution of different countries for HBV and HCV infection in 2016.

$\begin{array}{llll}\text { Country HBVHCV } & \text { percent no pent }\end{array}$

\begin{tabular}{|c|c|c|c|c|c|c|}
\hline Syria & & 70 & 45.8 & & 3 & 12 \\
\hline Turkey & 29 & 18.9 & & 1 & 4 & \\
\hline Indian subcontinent & 16 & 10.4 & & 3 & 12 & \\
\hline Far East & 16 & 10.4 & & 2 & 8 & \\
\hline Iran & 8 & 5.4 & & 6 & 24 & \\
\hline Europe & & 6 & 3.9 & & 7 & 28 \\
\hline Egypt & 2 & 1.3 & & 2 & 8 & \\
\hline USA & 2 & 1.3 & & 0 & 0 & \\
\hline Others & 4 & 2.6 & & 1 & 4 & \\
\hline Total & 153 & 100 & & 25 & 100 & \\
\hline
\end{tabular}

In 2016, the majority of the visitors were from Turkey, Iran, and India, Table -6.

Table 6: Number and percentage of the visitors according to their countries.

\begin{tabular}{lcc}
\hline Country & No of visitor percentage & \\
\hline Turkey & 6100 & 30.6 \\
\hline Iran & 3652 & 18.4 \\
\hline Indian Subcontinent & 3439 & 17.4 \\
\hline & & 13.9 \\
\hline
\end{tabular}




\begin{tabular}{ccc}
\hline Far East & 1745 & 8.8 \\
\hline Egypt & 858 & 4.3 \\
\hline Europe & 850 & 4.2 \\
\hline USA & 317 & 1.6 \\
\hline Others & 165 & 0.8 \\
\hline Total & 19896 & 100 \\
\hline
\end{tabular}

Among 19896 visitors in 2016, 16990 were males (85.4\%) who comprised $74.8 \%$ of positive cases and 2906 were females $(14.6 \%$ ) who comprised $25.2 \%$ of positive cases, Table 7.

Table 7: Gender distribution among visitors in 2016

\begin{tabular}{lll}
\hline Gender & $\begin{array}{l}\text { Visitors } \\
\text { Number }(\%)\end{array}$ & $\begin{array}{l}\text { Positive cases } \\
\text { Number }(\%)\end{array}$ \\
\hline Male & $16990(85.4)$ & $137(74.8)$ \\
Female & $2906(14.6)$ & $46(25.2)$ \\
Total & $19896(100)$ & $183(100)$ \\
\hline
\end{tabular}

Among a total number of $(19,896)$ individuals who were screened in 2016 , one hundred fifty three (153) visitors werepositive forHBV, with females having higher prevalence (12.7/1 000) compared to males (6.8/ 1000$)$, Table-8.

Table 8: Gender difference in rates of $\mathrm{HBV}$ in 2016.

\begin{tabular}{lllllc}
\hline Gender & HBV +ve & HBV - ve & Total & Prevalence & P-Value \\
\hline Males & 116 & 16874 & 16990 & $6.8 / 1000$ & 0.0011 \\
Females & 37 & 2869 & 2906 & $12.8 / 1000$ & (Chi Square test) \\
Total & 153 & 19743 & 19896 & & \\
\hline
\end{tabular}

Among total number of (19896) individuals who were screened in 2016, 25 visitors had positive test for $\mathrm{HCV}$, of these 19 cases were males and 6 cases were females. Although females had higher rates of HCV than males (2/1000 Vs 1.1/1000), these values were not statistically significant, Table 9.

Table 9: Gender difference in rates of $\mathrm{HCV}$ in 2016.

\begin{tabular}{lllllc}
\hline Gender & HCV+ve & HCV-ve & Total & Prevalence & p-Value \\
\hline Male & 19 & 16971 & 16990 & $1.1 / 1000$ & 0.294 \\
Female & 6 & 2900 & 2906 & $2 / 1000$ & (Chi Squared test) \\
Total & 25 & 19871 & 19896 & & \\
\hline
\end{tabular}

In the current study the minimum age was 18 years and maximum was 65 years. The mean age of individuals was $35.8 \pm 10$ years and $95 \%$ confidence Interval (CI) of $(33.92-37.70)$.

There was no significant age difference among HBV and HCV positiveindividuals, Table-10.

Table -10: Mean age difference among HBV, HCV and mean age of studied sample.

Number Mean Age/year SD $\quad$ P-Value




\begin{tabular}{lcccc}
\hline HBV & 153 & 35.88 & 9.95 & $\begin{array}{c}0.521 \\
\text { (Unpaired t-Test) }\end{array}$ \\
HCV & 25 & 37.26 & 10.05 & \\
\hline
\end{tabular}

The most common risk factors among the positive cases of HBV and HCV were dental procedures followed by surgery and family history; Tables $-11,12$.

Table -11: Risk factors among individuals who had positive tests for HBV infection.

\begin{tabular}{|c|c|c|}
\hline Risk Factors & Frequency & Percentage \\
\hline Dental procedure & 60 & 39.2 \\
\hline Surgery & 18 & 11.8 \\
\hline Positive family history & 16 & 10.5 \\
\hline Tattooing & 12 & 7.8 \\
\hline Blood Products Transfusion & 8 & 5.2 \\
\hline Multiple Sexual partners & 7 & 4.5 \\
\hline I.V Drug User & 2 & 1.3 \\
\hline Hemodialysis & 1 & 0.7 \\
\hline More than One & 17 & 11.2 \\
\hline No identifiable risk factor & 12 & 7.8 \\
\hline Total & 153 & 100 \\
\hline
\end{tabular}

Table -12: Risk Factors among individuals who had positive tests for HCV.

\begin{tabular}{llll}
\hline Risk Factors & Frequency & Percentage \\
\cline { 2 - 3 } & & \\
Dental procedure & 5 & 20 \\
Tattooing & 3 & 12 \\
Purgery & 2 & 8 \\
Positive family history & 2 & 8 \\
Multiple Sexual partners & 1 & 4 \\
Blood transfusion & 1 & 4 \\
More than One & 6 & 24 \\
No identifiable risk factor & 5 & 20 \\
\hline Total & 25 & 100 \\
\hline
\end{tabular}

Eighty nine point five percent of cases of HBV and $92 \%$ of HCV cases had no family history while $10.5 \%$ of patients with $\mathrm{HBV}$ and $8 \%$ of $\mathrm{HCV}$ cases had a positive Family History, males had higher maritalrate $(65.2 \%)$ than females $(45.7 \%)$.

Regarding awareness of their diagnosis, $70.5 \%$ of $\mathrm{HBV}$ and $76 \%$ of $\mathrm{HCV}$ positive cases had no prior diagnosis while $29.5 \%$ of $\mathrm{HBV}$ and $24 \%$ of $\mathrm{HCV}$ positive cases knew about their diagnosis

Regarding the previous vaccination against $\mathrm{HBV}, 47.7 \%$ of positive cases had no vaccination, $17 \%$ were vaccinated and $35.3 \%$ were unsure whether they are vaccinated or not, among those who were vaccinated against HBV, 53.8\% had a complete vaccination history, 19.3\% had incomplete vaccination, and $26.9 \%$ were uncertain about the doses they received.

Regarding the Occupation of the visitors, majority were laborers, housemaid and Office workers, Table-13.

Table-13: Occupation among the visitors in 2016.

\begin{tabular}{lrcc}
\hline Occupation & Number & Percent \\
\hline Laborer & 82 & 45.4 \\
Housemaid & 35 & 19.3 \\
Office worker & 19 & 10.5 \\
Teacher & & 12 & 6.7 \\
Free job 10 & 5.5 & & \\
\hline
\end{tabular}




\begin{tabular}{lcccc}
\hline Engineer & & 6 & & 3.3 \\
\hline $\begin{array}{l}\text { Health worker } \\
\text { Massage center }\end{array}$ & & 3 & 1.6 & 1.6 \\
\hline $\begin{array}{l}\text { others } \\
\text { Total }\end{array}$ & 3 & 11 & & 6.1 \\
\hline
\end{tabular}

\section{DISCUSSIONS}

Hepatitis B, C and HIV infections comprise a significant public health problem worldwide. They share the same route of transmissions, commonly sexually, blood transfusion, major and minor operations, needles contaminated with the blood of the infected patient, tattooing and vertical from mother to the child. [15], [16], [17], [18]. In our study, a total number of 275,979 foreigners who had visited Sulaimani Governorate and screened for HBV, HCV and HIV infections were analyzed. The prevalence of HBV, HCV and HIV infections were different according to the different countries, and some of our prevalence were different from their own country that may be due to the difference between our sample size and sample type.

In this study, the overall prevalence of HBV infection was $0.47 \%$ ( in 2013 through 2016) which is lower in comparison to the Aparna et al study (1965-2003), in which 17,029 records screened, 1800 report on the prevalence of HBsAg covering 161 countries all over the world were included, HBsAg seroprevalence was 3.61\% [23], this may be resulted from increase in the health education, screening, improvement of vaccination against HBV all over the world and advances in the treatments .

In 2015 and 2016 the prevalence of HBV infection was relatively higher than 2013 and 2014 . The increase in the prevalence may be related to the increase in the Syrian visitors and Refugees to our city who they had the highest prevalence of HBV infection in our study.

In 2016, The highest prevalence was among Syrian visitors which was $2.5 \%$ and this result is near to the result of Hussein et al study (2016) done in Duhok city on a total number of 880 Syrian refugees, 34 cases $(3.86 \%)$ had positive HBsAg [24].

In Muselmani et al study done in AL Assad university hospital on the blood donors (2013), they found the prevalence of HBV to be $1.3 \%$ [25], which is lower than in our study, probably this is because of the war that happened in that country since 2013 with near complete collapse of the health system. Beside this since beginning of the war in Syria hundreds of mass casualties had happened in the country with a large numbers of injuries, operations and blood transfusions.

The prevalence of HBV in Far East countries ( China, Korea , Japan , Indonesia, Malaysia and Philippines) was $0.9 \%$ in the current study, while it was nearly $8 \%$ in Liang et al study done in China in 2006 [26] and $16.7 \%$ in Stephen et al study (2003) done in Philippines, [27] both study were on their citizens, this may be related to the difference in the sample type and the improvement in Hepatitis B vaccination.

Among Turkish visitors, the prevalence of HBV was $0.48 \%$ in our study while it was $4.24 \%$ in Furuncuoğlu et al study (1995-2015), done in Istanbul on their 26001 citizens from 1995 through 2015 [28].

The prevalence of HBV among the Iranian visitors was $0.2 \%$ while it was $2.2 \%$ in Mostafa et al study (1990-2016), [29] in which they depended on multiple large studies on the prevalence of HBV infections from 1990 through 2016 done on their citizens.

This may be due to the acknowledgement of screening program in Kurdistan by the Turkish and Iranian visitors, with those who had a previous diagnosis with HBV do not visit and ask 
for residency in Kurdistan region, because they do not achieve Residency agreement by the Kurdistan Authorities.

In the current study, the prevalence of HBV among Europeans visitors was $0.7 \%$ which is near to the result of Rantala et al study (2008) which showed the prevalence to be between 0.5-1.5 percent in some Europeans countries [30].Among Americanvisitors HBV was 0.6\% which is near to the result of Wasley et al study in USA (1999-2006) which was 0.27\% [31].This low prevalence may be related to the good and proper health care including screening and vaccination program in European countries and American States.

In our study the overall prevalence of HCV infection was $0.097 \%$ from 2013 through 2016, while the overall world's prevalence was $1 \%$ in Sarah et al study [32]. This may be related to the size and the type of our sample as mentioned above. The highest prevalence of HCV infection was among the European visitors which was $0.82 \%$ that is near to the Sarah et al study that showed the prevalence of $\mathrm{HCV}$ infection in European countries to be, $0.5 \%$ in Hungary, $0.3 \%$ in Germany, $1.1 \%$ in Greece, $0.6 \%$ in Ireland, $1.1 \%$ in Italy, $0.4 \%$ in Sweden and $0.3 \%$ in UK. [32]. This may be due to the high rate of homosexuality, multiple sexual partners, increasing injecting drug abusers, increase Alcohol consumption and lack of a specific vaccine.

In this study, the overall prevalence was $0.01 \%$ (30 cases) in 2013 through 2016. In 2016 there were only 3 cases of HIV infection, all of them were females. The Sample size was too small to represent the prevalence of a specific country. In our study we did not have any confection of HBV, HCV and HIV.

The highest number of visitors were in 2013 and 2014 because the Kurdistan Region economically were growing rapidly till 2015 when the economic crises had happened and our Region attacked by Islamic state in Iraq and Sham (ISIS), the number of visitors sharply declined to its lowest level in 2016.

Majority of our visitors in 2016 were from Turkey $30.6 \%$ and Iran $18.4 \%$, that is related to being neighborhood to these countries, a strong economical relationship and presence of many companies representative of these countries in our region for which they employee their own citizens. Followed by visitors from Indian subcontinent $17.4 \%$, a group of developing countries where individual annual income is too low forcing them to work outside their countries and our region is one of those places to work in, on the other hand Syrian visitors and refugees comprise about $13.9 \%$ of total visitors and that is related to the state of war in the country that endangers their life making them flee for safety and livelihoods.

Among 19896 visitors in 2016, 16990 subjects were males (85.4\%) and 2906 subjects were females $(14.6 \%)$ of visitors. This may be due to that the majority of the visitors were laborers. Among these, 153 cases had positive test for HBV, of these 116 cases were males and 37 cases were females, with females having higher prevalence of HBV infection (1.28\%) compared to males $(0.68 \%)$, this may be due to low sample size of females compared to males in our study. Twenty five cases had positive test for HCV, of these 19 cases were males and6 cases were females. Although females had higher rates of HCV infection than males (2/1000 vs. $1.1 / 1000$ ) but these values were not statistically significant. Among 181 positive cases the distribution of viral type was as follow, $84.5 \% \mathrm{HBV}, 13.8 \% \mathrm{HCV}$ and $1.7 \% \mathrm{HIV}$. This is near to the result of Hussein et al study on Syrian refugees in Duhok city in which the majority of positive cases were HBV [21], this is related to the high infectivity of HBV in comparison to $\mathrm{HCV}$ and HIV. Age of the patients ranged between (18-65) years with mean age of individuals being $(35.81 \pm 9.9)$, majority were in $4^{\text {th }}$ decade of life, this is because of most of those who ask for residency are coming for working. This goes with Arab et al [33], Attarchi et al [34],Farhat et al [35] and Vahid et al study [36] which showed the mean age of their participants to be above 30 years. 
In the current study, there was no significant age difference among $\mathrm{HBV}+\mathrm{ve}$ and $\mathrm{HCV}+\mathrm{ve}$ individuals.

Unsafe medical practices including dental procedures could facilitate the transmission of the HBV infection. In our study about $39.2 \%$ of HBV cases and $20 \%$ of HCV cases had history of dental procedures .Surgical operations, family history, tattooing and blood transfusion were other major risk factors after dental procedures, which make a sense of importance of safe medical precautions in transmitting the disease. This goes with the study done by Reingold $e t$ al (2003), who found a high rate of HBV infection among those who had dental procedures. [37]. Also in Janahi et al study done in Bahrain, they screened more than 800,000 of foreigners and their citizens and found that most common risk factors were dental procedures $37.2 \%$ followed by surgery, family history and tattooing[38] . The family history is another important risk factor for $\mathrm{HBV}$ and $\mathrm{HCV}$ acquisition especially when the mother is the carrier , and this is the most common route of infection in the highly endemic regions [39], in Mohammad et al study it was shown that about $30 \%$ of HBV cases were having a family history[6]. In our study $10.5 \%$ of $\mathrm{HBV}$ positive cases and $8 \%$ of $\mathrm{HCV}$ positive cases had positive Family History; this may be related to unawareness of a previous diagnosis by majority of the visitors.

About the marital status of the patients, $65.2 \%$ of males and $45.7 \%$ of females were married, and the marriage is considered to be an important risk factor for getting infection with both HBV and HCV infections and this was found in Mohammad et al study [6].

Regarding the previous vaccination against $\mathrm{HBV}, 47.7 \%$ of positive cases had no vaccination history this may be related to the age of the patients and the vaccination program in their countries, $17 \%$ were vaccinated and $35.3 \%$ were unsure whether they are vaccinated or not. Among those who were vaccinated against $\mathrm{HBV}, 53.8 \%$ had a complete vaccination history, $19.3 \%$ had incomplete vaccination, and $26.9 \%$ were uncertain about the doses they received. Immunization reduced the prevalence of HBV infection among the populations worldwide .Ray Kim et al. (2009) showed that An encouraging trend is that the incidence of acute hepatitis B in the United States had declined as much as 80\% between 1987 and 2004, explained by effective vaccination programs and universal precautions in needle use and in healthcare in general [40].

Regarding the occupation of the positive cases, $45.4 \%$ were laborers, this may be related to low health education and high rate of work related accidents among this group, $19.3 \%$ were working as a housemaid, $10.5 \%$ were company officer and $6.7 \%$ were teachers. We had a group who did not have a specific occupation; these were the Syrian refugees coming to Kurdistan region to settle.

In a search to find out the fate of the positive cases we found that all positive visitors were sent back to their countries except the Syrian visitors who were sent to Kurdistan center for Gastroenterology/Health department in Sulaimani city to be treated accordingly.

\section{CONCLUSIONS}

The overall prevalence of HBV infection was much higher than HCV and HIV infections, and it was highest among the Syrian visitors. The prevalence of HCV infection was highest among Europeans.

The number of the visitors was largely declined in 2015 and 2016 as compared to 2013 and 2014 because of the economic crises and ISIS attack on our region.

The highest number of visitors was from Turkey, Iran and Syria. Majority of the visitors were males, married and in the $4^{\text {th }}$ decade of life. 
HBV positive cases had low rate and incomplete vaccination history. History of dental procedures, surgery, tattooing, and blood transfusion was high among HBV and HCV positive cases.

The authors disclose that they have no conflict of interest.

\section{REFERENCE}

[1] D. Samuel, R Muller, G Alexander: Educational Research, National Hepatitis B Virus Programme. Infect Dis. 2004; 234:221-332

[2] S. De Meyer, Z.J. Gong, W. Suwandhi. Organ and species specifity of HBV infection, journal of viral hepatitis.1997; 4,145-153.

[3] H. Norder, AM Courouce, LO. Magnius. Complete genomes, phylogenetic relatedness, and structural proteins of six strains of the hepatitis B virus, four of which represent two new genotypes. Virology.1994; 198(2):489-503.

[4] FV. Chisari, C. Ferrari. Hepatitis B virus immunopathology. Springer SeminImmunopathol. 1995. 17(23):261-81.

[5] D. Ganem,RJ. Schneider. Hepadna viridae: The Viruses and Their Replication. eds. Fields Virology, 4th ed. Philadelphia, Lippincott Williams \& Wilkins, 2001;2923-2969.

[6] OM. Mohammad, prevalence of hepatitis B virus infection among premarital people in Sulaimani Governorate.2012; IPMJ; volume (11) 635-641.

[7] A. MIbrahem, FA. Mohiadeen, M. Babakir. Prevalence, Knowledge and practices of Hepatitis B and C viruses among patients undergoing surgery in Sulaimani city .J rare DisordDiagn ther.2017; 2:6.

[8] N.R. Hussein, S.M. Haj, L.A. Almizari,A .A. Taha. The prevalence of Hepatitis B and C viruses among blood donors attending blood bank in Duhok, Kurdistan Region, Iraq. INTJ infection, volume 4, Issue 1, 2017, P.e39008

[9] "Hepatitis B FAQs for the Public". Centers for Disease Control and Prevention. Retrieved 2015-08-24

[10] WHO/Hepatitis B.http://www.who.int/mediacentre/factsheets/fs204/en/

[11] P. Karayiannis, HC.Thomas . BW. Mahy, MHV van Regenmortel , eds. Desk Encyclopedia of Human and Medical Virology. (2009) Boston: Academic Press. p. 110.

[12] S. Schillie, TV Murphy, M .Sawyer, Ly KE .Hughes, R. Jiles, et al. "CDC Guidance for Evaluating Health-Care Personnel for Hepatitis B Virus Protection and for Administering Postexposure Management". MMWR. Recommendations and reports: Morbidity and mortality weekly report. Recommendations and reports / Centers for Disease Control 2013; 62 (RR-10): 1-19.

[13] EJ, Aspinall, G. Hawkins, A. Fraser, SJ Hutchinson, SJ Goldberg D."Hepatitis B prevention, diagnosis, treatment and care: a review". Occupational Medicine. 2011;61 (8): 531-40.

[14] "Hepatitis C". World Health Organization (WHO). 2011. Retrieved 2011-07-13.

[15] K .MohdHanafiah,; J. Groeger,; AD Flaxman,; ST . Wiersma,."Global epidemiology of hepatitis C virus infection: new estimates of age-specific antibody to HCV seroprevalence. ". Hepatology (Baltimore, Md.).2013; 57 (4): 1333-42.

[16] Alter, MJ ."Epidemiology of hepatitis C virus infection". World journal of gastroenterology: WJG. 2007; 13 (17): $2436-41$

[17] RA Weiss."How does HIV cause AIDS?"Science. 1993; 260 (5112): 1273-9.

[18] DC. Douek, M. RA Roederer Koup ."Emerging Concepts in the Immunopathogenesis of AIDS". Annu. Rev. Med.2009; 60: 471-84

[19] UNAIDS, WHO. "2007 AIDS epidemic update" . 2007;p. 10. Retrieved 2008-03-12.

[20] UNAIDS (2016) 'Prevention Gap Report.

http://www.unaids.org/sites/default/files/media_asset/2016-prevention-gap-report_en.pdf

[21] "Worldwide AIDS \& HIV Statistics". AVERT. 31 December 2009. Archived from the original on 201104-06.Retrieved 26 January 2011.

[22] CL Celum, RW. Coombs, W. Lafferty, Inui TS, PH Louie, CA. Gates, et al. "Indeterminate human immunodeficiency virus type 1 western blots: seroconversion risk, specificity of supplemental tests, and an algorithm for evaluation". J Infect Dis. 1991; 164 (4): 656-664.

[23] S. Aprana, H. Johannes, R. Mikolajczy .Estimations of worldwide prevalence of chronic hepatitis B virus infection: a systematic review of data published between 1965 and 2003.the Lancet 2015; 10003:15461555.

[24] N.R. Hussein. Prevalence of HBV, HCV and HIV Infections among Syrian Refugees in Kurdistan Region, Iraq. Int J Infect. In Press: p. e39420.

[25] W. Muselmani, W. Habbal , F. Monem. Significance of screening antibodies to hepatitis B virus core antigen among Syrian blood donors. Transfus Med 2013; 23:265-8.

[26] XF. Liang Bi SL, WZ Yang, LD Wang, G. Cui, Cui FQ, et al. Epidemiological serosurvey of hepatitis B in China-declining HBV prevalence due to hepatitis B vaccination. Vaccine. 2009; 27:6550-6557.

[27] S N Wong, P. Janus Ong, Madeline Eternity D Labio, Oscar T Cabahug, Maria Lourdes O Daez, Erlinda V Valdellon ,et al. Hepatitis B infection among adults in the Philippines: A national seroprevalence study; World J Hepatol. 2013; 5(4): 214-219.

[28] Y. Furuncuoğlu, F. Sağlam, FF. Bölükbaş, C. Bölükbaş, R. Öztürk. Seroepidemiology of Hepatitis B Virus Infection in İstanbul: A 20-year Survey. Viral Hepat J. 2016; 22:88-91. 
[29] M. Salehi-Vaziri, F. Sadeghi, A. Almasi Hashiani, Mohammad Gholami Fesharaki, and S. Moayed Alavian .Hepatitis B Virus Infection in the General Population of Iran: An Updated Systematic Review and Meta-Analysis Hepat Mon. 2016; 16(4): e35577.

[30] M. Rantala, MJ van de Laar. Surveillance and epidemiology of hepatitis B and C in Europe - a review. EuroSurveill. 2008; 13(21):pii=18880.

[31] A. Wasley , D. Kruszon-Moran, W. Kuhnert, EP. Simard , L Finelli , G. McQuillan , B. Bell . The prevalence of hepatitis B virus infection in the United States in the era of vaccination 2010; 15; 202(2):192-201.

[32] S. Blach, S. Zeuzem, M. Manns, I. Altraif, Ann-SofiDuberg . Global prevalence and genotype distribution of hepatitis C virus infection in 2015: a modeling study. The Lancet Gastroenterology \&Hepatology 2016; Volume 5, No. 9, p558-567, 2005.

[33] M. Arab, A. AbasZadeh, B. Pour Aboli, L. Soleimani Zadeh, M. Shahsavari, M. Javadi. Prevalence of HBsAg positivity in blood donors in Bam, 1999-2002. SJIBTO. 2006; 3(3):277-80.

[34] Z. Attarchi, M. Ghafouri, B. Hajibaygi, SH Assari, Alavian SM. Donor deferral and blood-borne infections in blood donors of Tehran. SJIBTO. 2006; 2(7):353-64.

[35] A. Farhat, GH. Khademi, ShJ. Mazlouman. The prevalence of hepatitis B carrier state in Khorassan province of Iran. Saudi Medical Journal. 2003; 24(5):549-51.

[36] T .Vahid, SM. Alavian, A Kabir, J. Kafaee, B Yektaparast. Hepatitis B prevalence and risk factors in blood donors in Ghazvin, IR. Iran. Hepatitis Monthly. 2005; 5(4):117-22.

[37] A.L. Reingold, M. A. Kane, B. L. Murphy. Transmission of Hepatitis B by an Oral Surgeon, the Journal of Infectious Diseases. 2003; Volume 145, Issue 2Pp. 262-268.

[38] EM. Janahi. Prevalence and Risk Factors of Hepatitis B Virus Infection in Bahrain, 2000 through 2010.Ray R, ed. PLoS ONE. 2014;9(2):e87599.

[39] I. Gentile and G. Borgia. Vertical transmission of hepatitis B virus. Int J Women Health challenges and solutions.2014; 6: 605-611.

[40] MD. Ray Kim. Epidemiology of Hepatitis B in the United States, Hepatology. 2009; 49(5 Suppl): S28S34. 